\title{
Overview on population screening for carriers with germline mutations in mismatch repair (MMR) genes in China
}

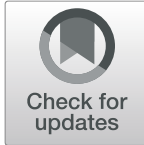

\author{
Min Zhang ${ }^{1}$ and Tianhui Chen ${ }^{2^{*}}$
}

\begin{abstract}
DNA mismatch repair (MMR) genes play an important role in maintaining genome stability. Germline mutations in MMR genes disrupt the mismatch repair function and cause genome instability. Carriers with MMR germline mutations are more likely to have MMR deficiency and microsatellite instability (MSI) than non-carriers and are prone to develop colorectal cancer (CRC) and extracolorectal malignancies, known as Lynch syndrome (LS). MMR gene testing for suspected mutation carriers is a reliable method to identify the mutation types and to discover mutation carriers. Given that carriers of MMR germline mutations have a higher risk of LS-related cancers (LS-RC) and a younger age at onset than non-carriers, early surveillance and regular screening of relevant organs of carriers are very important for early detection of related cancers. This review mainly focuses on the general status of MMR carriers, the approaches for early detection and screening, and the surveillance of MMR mutation carriers in China. Population screening of MMR germline mutation carriers in China will be helpful for early detection, early diagnosis and treatment of MMR mutation carriers, which may improve the 5-year survival, and reduce mortality and incidence rate in the long term.
\end{abstract}

Keywords: Population screening, Mismatch repair (MMR) genes, Lynch syndrome

\section{Introduction}

DNA mismatch repair (MMR) genes play an important role in maintaining genome stability. Germline mutations in MMR genes disrupt their mismatch repair function, cause genome instability and lead to increased cancer risk in the mutation carriers as represented by Lynch syndrome (LS) or hereditary nonpolyposis colorectal cancer (HNPCC) [1]. MMR genes, such as mutL homolog 1 (MLH1), MutS homolog 2 (MSH2), MutS homolog 6 (MSH6) and postmeiotic segregation increased 2 (PMS2), express MMR proteins, which are nucleic acid hydrolases that hydrolyze mismatched bases in

\footnotetext{
* Correspondence: chenth@zjcc.org.cn

${ }^{2}$ Department of Cancer Prevention/Experimental Research Center, Cancer Hospital of the University of Chinese Academy of Sciences (Zhejiang Cancer Hospital), Institute of Basic Medicine and Cancer (IBMC), Chinese Academy of Sciences, Hangzhou, China

Full list of author information is available at the end of the article
}

the process of DNA replication to make DNA replication accurate. However, germline mutations in MMR genes cause MMR protein deficiencies, which lead to mismatch repair during replication, resulting in microsatellite instability (MSI) and tumorigenesis. A largescale comprehensive screening found that 540 MMR variants were identified in the Chinese population, and the pathogenic/likely pathogenic carrier rate was $1.6 \%$. More than $90 \%$ of the variants only existed in Chinese ethnicity, showing an ethnic-specific nature [1]. In 2019, a new MLH1 c. $1896+5 \mathrm{G}>\mathrm{A}$ germline mutation was found in the Chinese LS-related lung and gastric cancer [2]. MMR mutation carriers susceptibly develop colorectal cancer (CRC) and other extracolorectal malignant tumors. It is a hereditary disease with an autosomal dominant inheritance. The incidence of LS in MMR mutation carriers is significantly higher than that in the 
general population, and the age at onset tends to be younger [3]. Nevertheless, LS patients usually have a decent clinical prognosis if they could be detected early and treated timely. Therefore, population screening for carries with MMR mutation has important clinical implications for LS-related cancers (LS-RC), such as improving 5-year survival, reducing the mortality, and reducing the incidence in the long-term. For example, regular colonoscopic screening for MMR mutation carriers could reduce CRC morbidity and mortality by $65-70 \%[4]$.

\section{LS-related cancers and MMR mutations in China}

Generally, LS-CRC located predominantly at proximal colon accounted for $2.7 \%$ of total CRC in China [4], and the average age at onset was under 50 years old among Chinese population [5, 6]. Gastric cancer was mainly extracolorectal cancer in Chinese families [7, 8], while endometrial cancer was the most common extracolorectal malignancy in Western countries [3]. In neighboring Japan, LS-related gastric cancer was also the most common extracolorectal tumor, with a standardized incidence ratio estimated at 20.2 [9]. Others reported that the LS-related liver cancer in Southern China [10] and LS-related lung cancer in Northeast China [11] were more frequent than endometrial cancer. However, the incidence of LS-related endometrial cancer had been increasing rapidly in China recently [12-14]. MLH1 and MSH2 are the most common germline mutations reported by clinical research, accounting for about $90 \%$ of all MMR gene mutations [15]. 11 MLH1 variants, such as c.1588_1590delTTC, c.1163_1164ins T and c.265G > T, and $18 \mathrm{MSH} 2$ variants, such as c.943-1G $>A$ and c.595T $>C$ were the high-frequency MMR variants in China [1]. In neighboring Korea and Japan, $\mathrm{MLH} 1$ and $\mathrm{MSH} 2$ was also the most common germline mutation $[9,16]$. In Pakistan, pathogenic/likely pathogenic MLH1/MSH2 variants account for a large proportion of $\mathrm{HNPCC} /$ suspected HNPCC colorectal cancer, mainly including three recurrent variants (MLH1 c.1358dup and c.2041G > A; MSH2 c.943-1G > C) [17]. Moreover, missense mutation was the most common mutation type in Chinese LS $[18,19]$. Although mutations in MMR genes do not mean that cancer will definitely occur, the related cancer risk in MMR mutation carriers is significantly higher than that of the general population. The average cumulative risk of LS-RC in MLH1 and MSH2 mutation carriers was $9.7 \%, 38.9 \%, 69.5 \%, 92.4 \%$, CRC was $9.7 \%, 36.4 \%, 66.7 \%, 81.3 \%$, and gastric cancer was 0 , $1.4 \%, 6.1 \%, 29.6 \%$, at age 30, 40, 50, 60 years old, respectively [20]. By the age at 70 years, the cumulative risk of $\mathrm{MLH1}$ and $\mathrm{MSH} 2$ mutation carriers for all LSRC would be $93.8 \%$ [15], which was higher than western countries. In addition, the mean age of CRC diagnosis in $M L H 1$ and $M S H 2$ mutation carriers was lower than that in MSH6 and PMS2 [16, 21]. The mutation rate and characteristics of $P M S 2$ were rare in China. Compared with $M L H 1$ mutation, patients with MSH2 mutation were more likely to develop synchronous and metachronous colon cancers [22]. Moreover, PMS2-deficient CRC was more common in the right colon and less in the rectum with poorly differentiated carcinoma [23]. LS-related endometrial cancer accounted for 4.78-5.4\% of total Chinese endometrial cancer, and MSH6 was likely to be a Chinese founder mutation for endometrial cancer $[10,24]$. The distribution of MMR gene pathogenic mutation in LS-CRC in China was as follows: MLH1 39.1\%, MSH2 33.9\%, MSH6 12.2\%, PMS2 9.6\% [4]. According to the studies from non-Asian population, $\mathrm{MSH} 2$ and $\mathrm{MSH} 6$ are the main susceptibility genes for ovarian cancer [25], MSH2 for urinary tract cancer [21], and PMS2 for breast cancer [26]. These LS-RC have not been fully studied in Asian population.

\section{Screening and diagnosing criteria and methods}

Amsterdam II criteria, revised Bethesda guideline, and Japanese criteria are common clinical diagnostic criteria for LS. Amsterdam criteria had lower sensitivity and higher specificity, while the revised Bethesda guideline had higher sensitivity and lower specificity [27]. In 2003, the Chinese LS screening criteria, also known as Fudan criteria, were proposed, which requests to include the below items1-2 and at least one item among items 3-5: (1) There are at least 2 cases of CRC confirmed by histology in the family; (2) Two of them are first-degree relatives (parents and children or siblings); (3) At least one patient with multiple CRC (including adenoma); (4) At least one case of CRC occurred before 50 years old; (5) At least one case in the family had LS-related extracolorectal malignancies (including gastric, endometrial, small bowel, ureteral, renal pelvis, ovarian, and hepatobiliary cancer). Actually, the sensitivity and accuracy of the Chinese criteria was slightly higher compared to Amsterdam criteria. According to the findings from Fudan University Shanghai Cancer Center (China), for the identification of Chinese HNPCC, the sensitivity, specificity and Youden index for Fudan criteria were slightly higher compared to those for Amsterdam criteria, i.e., $75 \%$, 58 and $33 \%$, respectively for Fudan criteria versus $50 \%, 81$ and $31 \%$, respectively for the Amsterdam criteria [22]. Furthermore, other investigations also confirmed that Amsterdam criteria may not be applicable to the diagnosis of HNPCC for Asian population [28]. However, most MMR mutation carriers were not easily identified by these clinical criteria [13]. Therefore, molecular screening strategies 
have greatly improved the diagnostic accuracy of LS. MMR gene testing is considered as the gold method for finding out MMR mutation carriers worldwide [15]. However, this high-cost technology has not yet been fully transformed into clinical applications in China. Currently, cheap accessible immunohistochemistry (IHC) technology has been widely used in China to detect MMR protein expressions [29]. MLH1 missense variant caused the defects in MLH1 and PMS2 proteins expressions [19], and MSH6 mutation and rarely $\mathrm{MSH} 2$ mutation resulted in loss of MSH6 protein expression [23]. Studies had shown that the sensitivity and specificity of IHC to detect MMR protein mutations were $66.7-90 \%$ and $89-97.3 \%$, respectively [13, 18, 23]. MSI testing is another common screening and diagnostic method. The sensitivity and specificity of MSI testing in the diagnosis of LSrelated endometrial cancer were 100 and $89.9 \%$, respectively [13]. Since approximately $15 \%$ of sporadic cancer patients had MSI in tumor tissues, MSI testing usually combined with other methods to reduce the diagnosis errors [13, 24]. The sensitivity and specificity of combined IHC and MSI detection approach reached 100 and $72.4 \%$, respectively for screening LS-

Table 1 The risk, age at diagnosis, regular screening method, starting age for surveillance, and survival of MMR mutation carriers

\begin{tabular}{|c|c|c|c|c|c|c|c|}
\hline LS-RC & $\begin{array}{l}\text { MMR } \\
\text { mutation } \\
\text { rate (\%) }\end{array}$ & $\begin{array}{l}\text { Cumulative } \\
\text { risk at age } 70 \\
\text { years }(\%)\end{array}$ & $\begin{array}{l}\text { Diagnosis } \\
\text { age } \\
\text { (years) }\end{array}$ & Screening method & $\begin{array}{l}\text { Starting age } \\
\text { for } \\
\text { surveillance }\end{array}$ & $\begin{array}{l}\text { 5-year } \\
\text { survival }\end{array}$ & Reference \\
\hline $\mathrm{CRC}$ & $\begin{array}{l}\text { MLH1: } \\
37.5-55.6 \\
\text { MSH2: } \\
33.8-50.0 \\
\text { MSH6: } \\
\text { 12.2-41.4 } \\
\text { PMS2:9.6- } \\
57.9\end{array}$ & $\begin{array}{l}\text { Mean:80 } \\
\text { MLH1: 52-81.7 } \\
\text { MLH2: 52-93.1 } \\
\text { MSH6: 10-22 } \\
\text { PMS2: 15-20 }\end{array}$ & $\begin{array}{l}\text { Mean:45.7 } \\
\text { Male:42 } \\
\text { Female:47 } \\
\text { MLH1:44 } \\
\text { MSH2:43 } \\
\text { MSH6:52 } \\
\text { PMS2:46 }\end{array}$ & Colonoscopy every $1-2$ years & $\begin{array}{l}\text { MLH1 and } \\
\text { MSH2 carriers: } \\
\text { 20-25 years } \\
\text { MSH6 and } \\
\text { PMS2 carriers: } \\
\text { 30-35 years }\end{array}$ & $\begin{array}{l}79.2- \\
84.2\end{array}$ & $\begin{array}{l}{[4,6,7,11,15} \\
16,19-24,31 \\
32,35-37]\end{array}$ \\
\hline $\begin{array}{l}\text { Endometrial } \\
\text { cancer }\end{array}$ & $\begin{array}{l}\text { MSH2:50- } \\
66 \\
\text { MLH1:24- } \\
40 \\
\text { MSH6:10- } \\
13 \\
\text { PMS2 } 9.6\end{array}$ & $\begin{array}{l}\text { Mean:51 } \\
\text { MLH1: } 42 \\
\text { MSH2: } 56 \\
\text { MSH6: } 45\end{array}$ & $\begin{array}{l}\text { Mean: 49- } \\
49.7 \\
\text { MLH1 or } \\
\text { MSH2:48- } \\
62 \\
\text { MSH6:55 } \\
\text { PMS2:49 }\end{array}$ & $\begin{array}{l}\text { Gnecological examination, pelvic ultrasound } \\
\text { and endometrial biopsy every year. After } \\
\text { giving birth to hysterectomy. }\end{array}$ & $30-35$ & 96.2 & $\begin{array}{l}{[3,5,12-14,25} \\
35,37]\end{array}$ \\
\hline $\begin{array}{l}\text { Gastric } \\
\text { cancer }\end{array}$ & $N R$ & $\begin{array}{l}\text { Male MLH1 or } \\
\text { MSH2>32.8 } \\
\text { Female MLH1 } \\
\text { or MSH2>27.1 }\end{array}$ & $\begin{array}{l}\text { Mean: 56- } \\
58.5 \\
\text { MLH1 or } \\
\text { MSH2: } 56 \\
\text { MSH6: } 63 \\
\text { PMS2: 70- } \\
78\end{array}$ & $\begin{array}{l}\text { Gastroscopy every } 3-5 \text { years and remove } \\
\text { Helicobacter pylori completely }\end{array}$ & $\begin{array}{l}30-35 \text { or } 40- \\
45\end{array}$ & $61-64$ & $\begin{array}{l}{[2,8,9,21,30} \\
35]\end{array}$ \\
\hline Lung cancer & $N R$ & $N R$ & 68.5 & $\begin{array}{l}\text { Appropriate imaging examination screen and } \\
\text { surveillance for carriers }\end{array}$ & $N R$ & $N R$ & {$[2,11,35]$} \\
\hline $\begin{array}{l}\text { Ovarian } \\
\text { cancer }\end{array}$ & $\begin{array}{l}\text { MLH1:38 } \\
\text { MLH2:47 }\end{array}$ & $\begin{array}{l}\text { MLH1 or MSH2: } \\
11-24 \\
\text { MSH6:3-10 } \\
\text { PMS2: } 6\end{array}$ & $\begin{array}{l}\text { Mean: } 45- \\
46 \\
\text { MLH1 or } \\
\text { MSH2: } 44 \\
\text { PMS2: } 42\end{array}$ & $\begin{array}{l}\text { Vaginal ultrasound and CA } 125 \text { detection, } \\
\text { bilateral fallopian tube-ovarian resection after } \\
\text { childbirth }\end{array}$ & $30-35$ & $52.5-59$ & {$[11,33,35,37]$} \\
\hline $\begin{array}{l}\text { Small bowel } \\
\text { cancer }\end{array}$ & $N R$ & $\begin{array}{l}\text { MLH1 or MSH2: } \\
3-6\end{array}$ & $\begin{array}{l}\text { MLH1 or } \\
\text { MSH2: } 47- \\
49 \\
\text { MSH6: } 54 \\
\text { PMS2: } 59\end{array}$ & $\begin{array}{l}\text { Upper gastrointestinal endoscopy every 3-5 } \\
\text { years }\end{array}$ & $30-35$ & NR & {$[28,33]$} \\
\hline $\begin{array}{l}\text { Urinary tract } \\
\text { cancer }\end{array}$ & NR & $1-12.6$ & $\begin{array}{l}\text { MLH1 or } \\
\text { MSH2: } 54- \\
60 \\
\text { MSH6: } 65\end{array}$ & Urinalysis and ultrasound per year & $30-35$ & $85-93$ & {$[22,28,33]$} \\
\hline $\begin{array}{l}\text { Pancreatic } \\
\text { cancer }\end{array}$ & $N R$ & 3.68 & $N R$ & $\begin{array}{l}\text { Endoscopic ultrasound and magnetic } \\
\text { resonance cholangiopancreatography based } \\
\text { on individual conditions }\end{array}$ & $N R$ & $<5$ & {$[28,33]$} \\
\hline $\begin{array}{l}\text { Central } \\
\text { nervous } \\
\text { tumors }\end{array}$ & NR & $1-3$ & $\begin{array}{l}\text { MLH1 or } \\
\text { MSH2: } 50 \\
\text { PMS2: } 45\end{array}$ & Routine physical examination every year & $25-30$ & 22 & {$[28,33]$} \\
\hline
\end{tabular}


related endometrial cancer in Chinese patients, though only 111 patients were evaluated in this study [13]. Another study including 738 CRC patients found that IHC and MSI testing were only moderately concordant in assessing MMR deficiency and MSI-high status [31], suggesting a combination of the two approaches to provide reliable data.

Generally, protein deficiency cases are identified using IHC (for BRAF V600E mutation) and/or MLH1 promoter methylation (for MLH1 mutation). The BRAF V600E mutation rate for MLH1-deficient CRC in Chinese population was significantly lower compared to Western population [4]. LS patients and mutation carriers were diagnosed by MMR gene testing from $M L H 1$ deficient cases with $M L H 1$ unmethylation, MLH1-deficient cases with wild-type BRAF CRC, and other protein deficiency cases [4]. Additionally, MLH1 promotermethylated CRC was also detected among individuals with family history of cancer and MLH1 splicing mutant $[4,32]$, indicating that family history of LS-RC is an important factor to avoid missing suspected case. Nextgeneration sequencing (NGS) and multiplex ligationdependent probe amplification (MLPA) are also promising approaches for gene testing, which can provide better and faster gene characteristics for cancer patients and high-risk individuals $[6,33,34]$.

\section{Follow-up surveillance and regular screening for MMR mutation carriers}

Individuals with $M L H 1$ or $M S H 2$ gene mutation are generally advised to undergo colonoscopy every $1-2$ years from age at 20-25 years or 5 years earlier than the youngest CRC patient in the family [15, 33, 35]. For MSH6 or PMS2 mutation carriers, some studies recommended colonoscopy surveillance should be started in later years [36, 37] (Table 1). Among mutation carriers, the colonoscopy surveillance group could detect more early cancers compared to the non-surveillance group $(70.0 \%$ vs. $36.5 \%$ ) [15]. Generally, CRC risk in mutation carriers increased with age, and male carriers with $M L H 1$ and MSH2 had a higher risk of LS-CRC compared to female carriers at age of 70 years [37]. Therefore, the counseling and management strategies for carriers with different MMR mutation shall be different [37]. In order to monitor and screen for endometrial and ovarian cancers, female mutation carriers were recommended to perform annually gynecological examination, pelvic ultrasound and endometrial biopsy from the age of 30-35 years [5, $28,35]$. Currently, preventive hysterectomy and oophorectomy are recommended for female carriers over 40 years or after childbirth [33]. Since gynecological screening has no effect on the increased risk of ovarian cancer reported in the literature, prophylactic oophorectomy is also recommended for female MMR mutation carriers over 35 years [35, 37]. It is also recommended to perform upper gastrointestinal endoscopy with gastric biopsy every 1-3 years starting from 30 to 35 years old and to remove helicobacter pylori completely [35]. Currently, surveillance guidelines for small intestine, urinary tract, lung, pancreas and brain cancers are still lacking. The risk, age at diagnosis, regular screening method, starting surveillance age, and survival of MMR mutation carriers, are presented in Table 1.

\section{Conclusions and future perspectives}

Germline mutations in MMR genes in Chinese population show an ethnic-specific nature. In China, $54.8 \%$ of family members with Lynch syndrome carried MMR gene mutations [15]. Further investigations on population screening for carriers with MMR germline mutations in Chinese population are highly warranted, which may promote to prevent precisely, to detect and diagnose early, and to treat effectively for MMR mutation-related cancers. Eventually, population screening may increase 5-year survival, and reduce mortality and incidence in the long term for LS-RC.

\section{Abbreviations}

MMR: DNA mismatch repair; MLH1: MutL homolog 1; MSH2: MutS homolog 2; MSH6: MutS homolog 6; PMS2: Postmeiotic segregation increased 2; LS: Lynch syndrome; LS-RC: Lynch syndrome-related cancers; HNPC

C: Hereditary nonpolyposis colorectal cancer; MSI: Microsatellite instability; CRC: Colorectal cancer; LS: Lynch syndrome; IHC: Immunohistochemistry; NGS: Next-generation sequencing; MLPA: Multiplex ligation-dependent probe amplification

\section{Acknowledgements}

Not applicable.

\section{Authors' contributions}

Tianhui Chen was responsible for the study concept and design. Min Zhang and Tianhui Chen drafted and revised the manuscript. The author(s) read and approved the final manuscript.

\section{Funding}

This work was supported by the grants from National Key R\&D Program of China (grant number:2017YFC0908200), Joint Sino-German Mobility Program" Clinical implications of familial colorectal cancer" [grant number: M-0008],

Startup Funds for Recruited Talents at Zhejiang Cancer Hospital, and Special project of Hangzhou Medical College (YS2021013).

Availability of data and materials

The articles used in this review are available from the corresponding author.

\section{Declarations}

Ethics approval and consent to participate

Not applicable.

Consent for publication

Not applicable.

Competing interests

The authors declare that they have no competing interests.

\section{Author details}

${ }^{1}$ School of Public Health, Hangzhou Medical College, Hangzhou, Zhejiang, China. ${ }^{2}$ Department of Cancer Prevention/Experimental Research Center, Cancer Hospital of the University of Chinese Academy of Sciences (Zhejiang 
Cancer Hospital), Institute of Basic Medicine and Cancer (IBMC), Chinese Academy of Sciences, Hangzhou, China.

\section{Received: 21 December 2020 Accepted: 20 April 2021 Published online: 01 May 2021}

\section{References}

1. Zhang L, Bhaskaran SP, Huang T, Dong H, Chandratre $K$, Wu $X$, et al. Variants of DNA mismatch repair genes derived from 33,998 Chinese individuals with and without cancer reveal their highly ethnic-specific nature. Eur J Cancer. 2020;125:12-21.

2. Chen X, Li X, Liang H, Wei L, Cui Q, Yao M, et al. A new mutL homolog $1 \mathrm{C}$. $1896+5 G$ > A germline mutation detected in a Lynch syndromeassociated lung and gastric double primary cancer patient. Mol Genet Genomic Med. 2019;7:e787.

3. Gordhandas S, Kahn RM, Gamble C, Talukdar N, Maddy B, Baltich Nelson B, et al. Clinicopathologic features of endometrial cancer with mismatch repair deficiency. Ecancermedicalscience. 2020;14:1061.

4. Dong L, Jin X, Wang W, Ye Q, Li W, Shi S, et al. Distinct clinical phenotype and genetic testing strategy for Lynch syndrome in China based on a large colorectal cancer cohort. Int J Cancer. 2020;146:3077-86.

5. He Y, Tao X, Huang F, Jia N, Du Y, Yu J, et al. Clinicopathologic features of endometrial cancer in Chinese patients younger than 50 years with a family history of cancer. Med (Baltim). 2018;97:e12968.

6. Gong $R$, He Y, Liu XY, Wang HY, Sun LY, Yang XH, et al. Mutation spectrum of germline cancer susceptibility genes among unselected Chinese colorectal cancer patients. Cancer Manag Res. 2019;11:3721-39.

7. Wang XL, Yuan Y, Zhang SZ, Cai SR, Huang YQ, et al. Clinical and genetic characteristics of Chinese hereditary nonpolyposis colorectal cancer families. World J Gastroenterol. 2006;12:4074-77.

8. Zhu F, Pan D, Zhang H, Ye Q, Xu P, Pan J. Single-center study of Lynch syndrome screening in colorectal polyps. Hered Cancer Clin Pract. 2019;17:9.

9. Ikenoue T, Arai M, Ishioka C, Iwama T, Kaneko S, et al. Importance of gastric cancer for the diagnosis and surveillance of Japanese Lynch syndrome patients. J Hum Genet. 2019;64:1187-94.

10. Luo DC, Cai Q, Sun MH, Ni YZ, Ni SC, Chen ZJ, et al. Clinicopathological and molecular genetic analysis of HNPCC in China. World J Gastroenterol. 2005; 11:1673-79

11. Li XX, Tang YX, Sun GP, Li X, Zhao M, Yan YF, et al. Analysis of features of extracolonic carcinoma spectrum in northeast Chinese with hereditary nonpolyposis colorectal cancer. Chin J Bases Clin General Surg. 2012;19:28891.

12. Tian W, Bi R, Ren $Y$, He H, Shi S, Shan B, et al. Screening for hereditary cancers in patients with endometrial cancer reveals a high frequency of germline mutations in cancer predisposition genes. Int J Cancer. 2019;145: 1290-98.

13. Chao X, Li L, Wu M, Ma S, Tan X, Zhong S, et al. Comparison of screening strategies for Lynch syndrome in patients with newly diagnosed endometrial cancer: a prospective cohort study in China. Cancer Commun (Lond). 2019:39:42

14. Wang Y, Xue F, Broaddus RR, Tao X, Xie SS, Zhu Y. Clinicopathological features in endometrial carcinoma associated with Lynch syndrome in China. Int J Gynecol Cancer. 2009;19:651-56.

15. Fu L, Sheng JQ, Li XO, Jin P, Mu H, Han M, et al. Mismatch repair gene mutation analysis and colonoscopy surveillance in Chinese Lynch syndrome families. Cell Oncol (Dordr). 2013;36:225-31.

16. Shin YK, Heo SC, Shin JH, Hong SH, Ku JL, et al. Germline mutations in MLH1, MSH2 and MSH6 in Korean hereditary non-polyposis colorectal cancer families. Hum Mutat. 2004:24:351.

17. Rashid MU, Naeemi H, Muhammad N, Loya A, Lubiński J, Jakubowska A, et al. Prevalence and spectrum of $\mathrm{MLH} 1, \mathrm{MSH} 2$, and MSH6 pathogenic germline variants in Pakistani colorectal cancer patients. Hered Cancer Clin Pract. 2019;17:29.

18. Sheng JQ, Fu L, Sun ZQ, Huang JS, Han M, Mu H, et al. Mismatch repair gene mutations in Chinese HNPCC patients. Cytogenet Genome Res. 2008; 122:22-7.

19. Zaib T, Zhang C, Saleem K, Xu L, Qin Q, Wang Y, et al. Functional Characterization of a Missense Variant of MLH1 Identified in Lynch Syndrome Pedigree. Dis Markers. 2020;2020:8360841.

20. Zhang Y, Zhang ZF, Sheng J, Li SR, Zhang F, Ren YM, et al. Difference of cumulative cancer risk between man and woman hMLHI or hMSH2 germline mutation carriers in hereditary nonpolyposis colorectal cancer familes. Chin J Gastroneterol Hepatol. 2011:20:508-12.

21. Marques-de-Sá I, Castro R, Pita I, Dinis-Ribeiro M, Brandão C. Cancer-risk by family history and mismatch-repair mutation in Lynch syndrome. Scand J Gastroenterol. 2020;55:701-05.

22. Liu F, Yang L, Zhou X, Sheng W, Cai S, Liu L, et al. Clinicopathological and genetic features of Chinese hereditary nonpolyposis colorectal cancer (HNPCC). Med Oncol. 2014;31:223.

23. Zeng Z, Yan Q, Chen G, Zhang X, Huang J, Fu K, et al. Characteristics of colorectal carcinoma patients with PMS2 defects detected by immunohistochemistry. Eur J Cancer Prev. 2020. doi:https://doi.org/10.1097/ CEJ.0000000000000620.

24. Ren C, Liu Y, Wang Y, Tang Y, Wei Y, Liu C, et al. Identification of novel Lynch syndrome mutations in Chinese patients with endometriod endometrial cancer. Cancer Biol Med. 2020;17:458-67.

25. Pavanello M, Chan IH, Ariff A, Pharoah PD, Gayther SA, Ramus SJ. Rare Germline Genetic Variants and the Risks of Epithelial Ovarian Cancer. Cancers (Basel). 2020;12:3046.

26. Sheehan M, Heald B, Yanda C, Kelly ED, Grobmyer S, Eng C, et al. Investigating the Link between Lynch Syndrome and Breast Cancer. Eur J Breast Health. 2020;16:106-9.

27. Gao XH, Zhang W, Liu LJ, Yan HL. [Comprehensive application of various screening strategies of Lynch syndrome]. Chin J Gastrointest Surg. 2019;22: 684-88.

28. Chew MH, Koh PK, Ng KH, Lim JF, Ho KS, et al. Phenotypic characteristics of hereditary non-polyposis colorectal cancer by the Amsterdam criteria: an Asian perspective. ANZ J Surg. 2008;78:556-60.

29. Zhao C, Feng Z, He H, Zang D, Du H, Huang H, et al. Protein expressionbased classification of gastric cancer by immunohistochemistry of tissue microarray. PLOS ONE. 2020;15:e0238836.

30. Bai H, Wang R, Cheng W, Shen Y, Li H, et al. Evaluation of Concordance Between Deficient Mismatch Repair and Microsatellite Instability Testing and Their Association with Clinicopathological Features in Colorectal Cancer. Cancer Manag Res. 2020;12:2863-73.

31. Ntavatzikos A, Spathis A, Patapis P, Machairas N, Vourli G, Peros G, et al. TYMS/KRAS/BRAF molecular profiling predicts survival following adjuvant chemotherapy in colorectal cancer. World J Gastrointest Oncol. 2019;11: 551-66.

32. Sobocińska J, Kolenda T, Teresiak A, Badziąg-Leśniak N, Kopczyńska M, Guglas K, et al. Diagnostics of Mutations in MMR/EPCAM Genes and Their Role in the Treatment and Care of Patients with Lynch Syndrome. Diagnostics. 2020;10:786

33. Omark J, Vilar E, You YN, Dunnington L, Noblin S, Stevens B, et al. Patients with unexplained mismatch repair deficiency are interested in updated genetic testing. Hered Cancer Clin Pract. 2020;18:19.

34. Yurgelun MB, Hampel H. Recent Advances in Lynch Syndrome: Diagnosis, Treatment, and Cancer Prevention. Am Soc Clin Oncol Educ Book. 2018;38: 101-9.

35. Chen W, Pearlman R, Hampel H, Pritchard CC, Markow M, Arnold C, et al. MSH6 immunohistochemical heterogeneity in colorectal cancer: comparative sequencing from different tumor areas. Hum Pathol. 2020;96: 104-11.

36. Wang C, Wang Y, Hughes KS, Parmigiani G, Braun D. Penetrance of Colorectal Cancer Among Mismatch Repair Gene Mutation Carriers: A MetaAnalysis. JNCI Cancer Spectr. 2020;4:pkaa027.

37. Dębniak T, Gromowski T, Scott RJ, Gronwald J, Huzarski T, et al. Management of ovarian and endometrial cancers in women belonging to HNPCC carrier families: review of the literature and results of cancer risk assessment in Polish HNPCC families. Hered Cancer Clin Pract. 2015:13:3.

\section{Publisher's Note}

Springer Nature remains neutral with regard to jurisdictional claims in published maps and institutional affiliations. 